\section{The Scottish dental practitioner's role in managing child abuse and neglect}

\author{
C. M. Harris, ${ }^{* 1}$ R. Welbury ${ }^{2}$ and A. M. Cairns ${ }^{3}$ \\ VERIFIABLE CPD PAPER
}

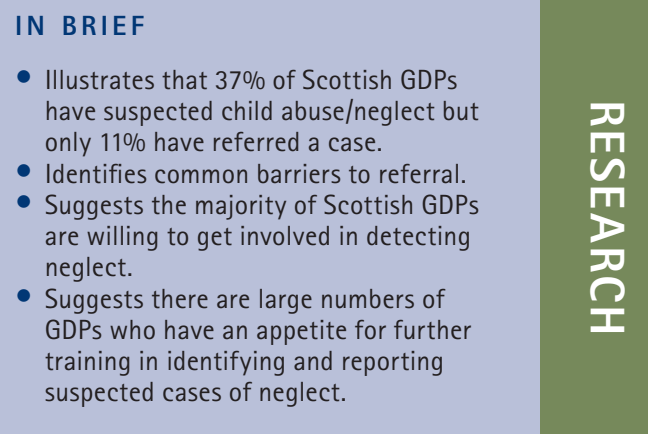

\begin{abstract}
Background In 2005 Cairns et al. published a paper (Int J Paediatr Dent 2005; 15: 310-318) examining the role of the general dental practitioner (GDP) in child protection (CP) in Scotland. This involved a questionnaire sent out to Scottish GDPs in 2003. Subsequently in 2006 all UK dental practices were sent Child protection and the dental team, a manual detailing roles and responsibilities with regard to CP. During this time the profile of CP within dentistry increased. There has been no published research since 2006 investigating whether the gap between the proportion of GDPs who suspect child abuse/ neglect in their patients and those who refer cases has changed. Aim The aim of this research was to investigate whether this gap has changed between 2003 and 2010. Method A postal questionnaire based on that used by Cairns et al. was sent to 50\% of GDPs in Scotland in March 2010. Results The response rate was 52\% (53\% male). Some 29\% and 55\% of respondents had received undergraduate or postgraduate training in child protection respectively. Over two thirds (37\%) had suspected child abuse/neglect in one or more of their paediatric patients but only $11 \%$ had referred a case. The most common factor affecting the decision to refer was 'lack of certainty of the diagnosis' (74\%). Some 77\% thought that abused/neglected children had an increased caries increment and 73\% of dentists were willing to get involved in detecting neglect. Conclusion Dentists in Scotland appear to be suspecting and referring more cases of child abuse/neglect than previously. The vast majority are willing to get involved in detecting neglect.
\end{abstract}

\section{INTRODUCTION}

Dentists are in a position to identify physical abuse in their paediatric patients. ${ }^{1-4}$ They may be even better placed to diagnose dental neglect as a stand alone health issue or as part of an overall picture of general neglect. ${ }^{5}$ Additionally previous research has shown that children who have experienced abuse/neglect have a higher incidence of caries and other oral diseases. ${ }^{6-8}$

Previous work by Cairns et al. ${ }^{9}$ published in 2005 showed that although 29\% of dentists in Scotland in 2003 had suspected child abuse only $8 \%$ had referred these cases on to the appropriate authorities. This

\footnotetext{
${ }^{1}$ Specialist Registrar in Paediatric Dentistry, ${ }^{2}$ Professor and Honourary Consultant, ${ }^{3}$ Senior Clinical University Teacher and Honourary Consultant, Glasgow Dental Hospital and School, 378, Sauchiehall Street, Glasgow, G2 3JZ

${ }^{*}$ Correspondence to: Christine Harris Email: c.harris1@nhs.net
}

\section{Online article number E24}

Refereed Paper - accepted 26 January 2013

DOI: 10.1038/sj.bdj.2013.435

${ }^{\circledR}$ British Dental Journal 2013; 214: E24 disparity has also been described in the UK by Welbury et al. ${ }^{10}$ with regard to general dental practitioners (GDPs), by Harris et al. ${ }^{11}$ for dentists and dental care professionals with an interest in paediatric dentistry and by Chadwick et al. for dental therapists. ${ }^{12}$ The phenomenon of under-reporting is also an international problem..$^{3,13-19}$

In 2006 all dental practices in Scotland were sent a document entitled Child protection and the dental team..$^{20}$ This is a training manual aiming to improve knowledge on the signs and symptoms of child abuse and neglect along with information regarding appropriate generic referral protocols. In addition to this, NHS Education for Scotland started to fund inter-agency postgraduate training courses for dental teams on the topic of child protection (CP). Training in $\mathrm{CP}$ is also a core topic in vocational training/dental foundation programmes and forms part of the undergraduate dental curriculum in UK dental schools.

In addition there have been recent discussions on issues of dental neglect as a stand alone issue and also its relationship to an overall picture of general neglect in children. This has led to the publication of guidance on this issue by the British Society of Paediatric Dentistry (BSPD). ${ }^{21}$

Overall responsibilities of UK dental teams with regard to $\mathrm{CP}$ are clearly outlined by the General Dental Council. ${ }^{22}$

\section{AIMS}

The aims of this research were to assess current knowledge and behaviours of GDP's in Scotland with regard to $\mathrm{CP}$ and to consider whether the increased amount of CP training had any impact on this. Another goal was to assess how willing GDPs are to get involved in detecting child neglect.

\section{MATERIALS AND METHODS}

A postal questionnaire based on that devised by Cairns et al. ${ }^{9}$ was sent out to $50 \%$ of the GDP's in Scotland $(\mathrm{n}=1,215)$. The questionnaire consisted of mainly closed 'yes or no' questions. The sample was selected by listing all the GDPs in Scotland by health board alphabetically and sending every second GDP a questionnaire. This 
unbiased selection system also gave an accurate representation from each health board. The original questionnaire was modified to include questions regarding neglect as well as abuse, and piloted with a small group of GDPs and recently qualified graduates. A prepaid return envelope was enclosed with each questionnaire. The questionnaires were posted in March 2010 with a covering letter. A second mailing was sent in July 2010 to non-respondents. All respondents were assigned a unique study number to ensure anonymity. Data was entered into an SPSS 17.0 database. Although there was missing data on some returned questionnaires all the received data was entered and where GDPs had not answered a particular question it was assumed that their response to a closed 'yes or no' question was 'no'. Where there is missing data for other questions the numbers of GDPs who did answer the question is reported in the results.

\section{Statistical analysis}

Statistical analysis was performed using SPSS 17.0. Analysis consisted primarily of observational statistics. Chi-squared analysis and the generation of p-values were used in cross-tabulations to explore comparisons.

\section{RESULTS}

\section{Demographics}

The response rate was 52\%; this represents the views of 628 Scottish GDPs. Fifty-three percent of respondents were male. The majority of respondents had practices based in Greater Glasgow and Clyde (25\%), Lothian (15\%), Lanarkshire (10\%), Tayside (9\%) and Grampian (8\%) health boards with the remaining respondents spread throughout the remaining nine health boards in Scotland. The majority of respondents worked in independent NHS practices (85\%). Fifty percent of respondents were 20 years or more post qualification. These demographics were representative of the spread of GDPs in Scotland as a whole. ${ }^{23}$

\section{Training and access to child protection guidelines}

Twenty-nine percent $(n=185)$ of respondents had received formal undergraduate training in CP. Respondents were less likely

Table 1 Factors influencing GDPs' decision to refer a suspected case of abuse/neglect

\begin{tabular}{|l|l|l|}
\hline Factor influencing decision & $\begin{array}{l}\% \text { GDPs whose decision is } \\
\text { influenced in this study }\end{array}$ & $\begin{array}{l}\% \text { GDPs whose decision is influenced } \\
\text { in Cairns et al. 2005 }\end{array}$ \\
\hline Concerns of impact on practice & $6 \%(n=38)$ & $11 \%$ \\
\hline Fear of violence to child & $52 \%(n=324)$ & $34 \%$ \\
\hline Fear of violence to GDP & $31 \%(n=195)$ & $31 \%$ \\
\hline Fear of litigation & $35 \%(n=220)$ & $48 \%$ \\
\hline $\begin{array}{l}\text { Fear consequences to child from } \\
\text { statutory agencies }\end{array}$ & $46 \%(n=286)$ & $52 \%$ \\
\hline $\begin{array}{l}\text { Lack of knowledge of referral } \\
\text { procedures }\end{array}$ & $43 \%(n=271)$ & $71 \%$ \\
\hline Lack of certainty of diagnosis & $74 \%(n=465)$ & $88 \%$
\end{tabular}

Table 2 Percentage of GDPs concerned about a child due to four different worrying behaviours

Option $\%$ GDPs concerned

Irregular attendance

Failure to complete treatment

Returning in pain at repeated intervals

Requiring repeat GA for extractions

$47 \%(n=296)$

$43 \%(n=270)$

$45 \%(n=285)$

$37 \%(n=233)$

Table 3 Difference in percentage of GDPs concerned about a child due to four different worrying behaviours when training or reading Child protection and the dental team is considered

\begin{tabular}{l|l|l|l|}
\multirow{2}{*}{ Option } & \multicolumn{2}{l}{ \%GDPs concerned about option in each group } \\
\cline { 2 - 4 } & $\begin{array}{l}\text { With any training } \\
\text { or seen manual }\end{array}$ & $\begin{array}{l}\text { No training and } \\
\text { never seen manual }\end{array}$ & P value \\
\hline Irregular attendance & $57 \%$ & $38 \%$ & 0.003 \\
\hline Failure to complete treatment & $53 \%$ & $32 \%$ & 0.001 \\
\hline Returning in pain at repeated intervals & $55 \%$ & $38 \%$ & 0.008 \\
\hline Requiring repeat GA for extractions & $47 \%$ & $34 \%$ & 0.05 \\
\hline $\begin{array}{l}\text { In all cases a higher proportion of the GDPs in the group who had received training or had read Child protection and the dental team were } \\
\text { concerned about the options, than in the group who had not received training or read Child protection and the dental team }\end{array}$
\end{tabular}

to have received undergraduate $\mathrm{CP}$ training with increasing years since qualification ( $\mathrm{p}<0.001)$. Fifty-five percent $(\mathrm{n}=344)$ of respondents had received some postgraduate training in $\mathrm{CP}$, most commonly a 'one-off' lecture.

Only 22\% ( $\mathrm{n}=141)$ of GDPs who returned the questionnaire had been sent a copy of their local area CP guidelines when they first started work at their practice; however, 55\% $(n=347)$ responded positively when asked if they had read the 2006 manual Child protection and the dental team.

In total 15\% of Scottish GDPs in this sample had never had any form of $\mathrm{CP}$ training and nor had they read Child protection and the dental team.

\section{Practice}

Thirty-seven percent $(n=235)$ of respondents had suspected child abuse/neglect in one or more of their paediatric patients but only $11 \%(\mathrm{n}=72)$ of all respondents had referred a case. This left 163 (26\%) respondents who reported suspecting child abuse or neglect who either did not refer the case or declined to answer the question about referring. Of those 235 respondents who had suspected child abuse/neglect 94\% ( $\mathrm{n}=220)$ had either had some form of CP training or had read Child protection and the dental team, this finding was statistically significant ( $\mathrm{p}<0.001)$. When looking at the 72 GDPs who had referred $96 \%(n=69)$ of those respondents had either had some form of CP training or had 


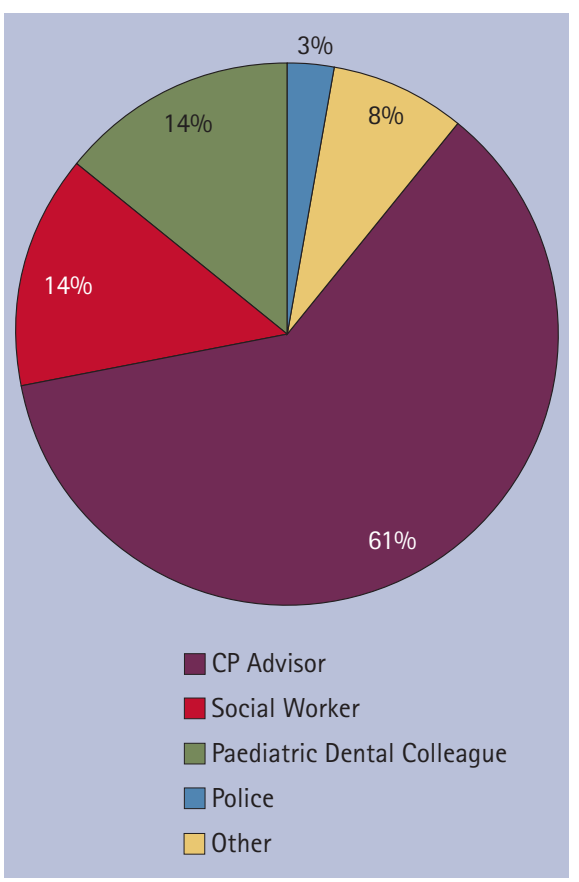

Fig. 1 Graph of agencies to whom GDPs would refer a hypothetical case of suspected child abuse/neglect

read Child protection and the dental team. Six percent $(n=37)$ of all respondents had seen a definite case of child abuse/neglect in the last six months. The questionnaire also directly asked, as a separate question, whether the GDPs had ever suspected a child was being abused or neglected but not referred the case. Seventeen percent $(\mathrm{n}=107)$ admitted to this with $81 \%(\mathrm{n}=87)$ of these GDPs having recorded their observations in the patient's case notes.

Of all the GDPs who returned the questionnaire $77 \%(\mathrm{n}=485)$ the perception was that abused/neglected children had a higher caries increment.

\section{Factors influencing practice}

The GDPs were also asked about various factors that may affect their decision to refer a suspected case of child abuse/ neglect (Table 1). The most common factor that affected their decision was 'lack of certainty of the diagnosis' with 74\% saying this would affect their decision. The least likely factor to affect their decision was 'concerns about impact on the practice' with only $6 \%$ citing this as a factor influencing their decision to refer.

The GDPs were then asked, 'If you have pointed out a child's dental problems and offered appropriate and acceptable treatment did any of the following make you concerned about a child?' The percentages of GDPs citing each of the following

\section{Table 4 Willingness of GDPs to get involved in detecting neglect}

\begin{tabular}{|l|l}
\hline I am willing to get involved in detecting neglect & \%GDPs
\end{tabular}

\begin{tabular}{l|l}
\hline Strongly agree & $21 \%(n=132)$ \\
\hline Agree & $52 \%(n=324)$ \\
\hline Neither agree or disagree & $19 \%(n=120)$ \\
\hline Disagree & $3 \%(n=19)$ \\
\hline Strongly disagree & $2 \%(n=11)$ \\
\hline Missing answer & $3 \%(n=22)$
\end{tabular}

factors as being of concern is shown in Table 2:

- irregular attendance

- failure to complete treatment

- returning in pain at repeated intervals

- requiring repeat GA for extractions.

When these results were cross tabulated with whether a GDP had received any CP training or had read Child protection and the dental team there was a significant difference between those who had training or had seen the manual compared to those who had not. For each of the four options (irregular attendance, failure to complete treatment, returning in pain at repeated intervals and requiring repeat GA for extractions) the proportion of GDPs who were concerned was higher for those who had training or had read the manual (Table 3).

\section{Child protection procedures}

Five hundred and ninety-three GDPs answered when asked what they would do in a hypothetical suspected case of child abuse/neglect and of these 60\% ( $\mathrm{n}=358$ ) would refer to their $\mathrm{CP}$ advisor. This is illustrated in Figure 1. The role of a CP advisor in Scotland is discussed later in this paper. A social worker was the next most common choice for referral $(15 \%, \mathrm{n}=86)$ followed by a paediatric dental colleague $(14 \%, n=82)$, police $(3 \%, n=19)$ and other $(8 \%, n=46)$. 'Other' was most commonly the child's general medical practitioner (GMP). When asked if they would prefer to discuss their suspicions with a dental colleague before referring $88 \%(\mathrm{n}=526)$ agreed and a further $37 \%(n=203)$ would choose to consult someone else before referring, most commonly the child's GMP.

Only 31\% of all respondents $(n=193)$ knew who their CP advisor was. When looking at those GDPs with no training/had not read Child protection and the dental team only 2.4\% knew who their CP advisor was compared to $38 \%$ of those who were trained or had read the manual ( $\mathrm{p}<0.001)$.

Twenty-one percent $(\mathrm{n}=129)$ of the responding GDPs were aware that interagency $\mathrm{CP}$ training courses were available in their area.

Most $(63 \%, n=398)$ felt that GDPs or other members of the dental team were well placed to recognize signs of abuse/ neglect, however only 19\% thought that GDPs were adequately informed about issues of CP. This was reflected in 73\% ( $n=458$ ) saying that they would like further training to identify child neglect and $78 \%$ ( $\mathrm{n}=489$ ) wanting further training on the mechanisms of reporting suspected cases of neglect. Eighty-eight percent of respondents thought that $\mathrm{CP}$ should be part of dental vocational training.

The GDPs were asked to indicate whether they agreed with the following statement, 'I am willing to get involved in detecting neglect', with a scale from strongly agree to strongly disagree. The spread of answers is shown in Table 4. This illustrates that 73\% of GDPs who are willing to be involved in detecting neglect in their paediatric patients, with only 5\% disagreeing they are willing to be involved and a further 19\% neither agreeing nor disagreeing.

Out of all the responding GDPs only 1\% $(\mathrm{n}=4)$ sat on a multi-agency child protection committee and those that did were often involved through their church rather than as a dentist.

\section{DISCUSSION}

\section{Training and access to child protection guidelines}

Thirty percent of respondents had received $\mathrm{CP}$ training as an undergraduate. This 
is higher than found by Cairns et al. in 2005. The more recently qualified dentists were more likely to have had CP training as an undergraduate. Some 55\% of respondents had received postgraduate training in $\mathrm{CP}$ which is more than double that found by Cairns et al. ${ }^{9}$ There has been an increase in the amount of $\mathrm{CP}$ training available to dentists in Scotland since 2005, most notably the inclusion of CP section 63 courses in Scotland. Child protection is also one of the topics covered in all vocational training schemes in Scotland. However, at present CP is not one of the GDC's core continued professional development topics, the authors continue to campaign to have this rectified.

Twenty-two percent of GDPs returning this questionnaire had been sent a copy of their local area CP guidelines. This is higher than found by Cairns et al. ${ }^{9}$ and in the intervening seven years since the previous study all dental practices in Scotland were sent a copy of Child protection and the dental team manual. This study found that over half of the responding GDPs had read this document. However, as all the dental practices were sent the manual, which is also freely available online, it remains disappointing that this number is not higher.

Despite the increased proportion of dentists completing $\mathrm{CP}$ training/familiar with Child protection and the dental team there was a large number of GDPs who wanted further training in identifying and reporting cases of neglect (73\% and 78\% respectively).

\section{Practice}

Over a third (37\%) of the dentists had suspected child abuse/neglect in one or more of their paediatric patients. This is higher than the results found by Cairns et al. ${ }^{9}$ and may suggest an increased awareness of child abuse/neglect among dentists. A significant number of those dentists who had suspected abuse/neglect had either had some form of CP training or had read Child protection and the dental team. This suggests training and access to the manual may increase awareness. Alternatively, this difference could be as a result of dentists who have suspected cases of abuse/ neglect actively seeking out training or reading the manual to help them in referring cases.
Seventeen percent of the dentists admitted they had suspected a case of child abuse/neglect but had not reported it when directly questioned about this issue. This is slightly lower than the results from the 2005 study $^{9}$ which may suggest that more of those dentists who do suspect cases are referring them. In addition the proportion who said they had referred a suspected case $(11 \%)$ is also slightly greater than found by Cairns et al. ${ }^{9}$ giving further support to this hypothesis. For the $17 \%$ who admitted they had suspected but not referred $81 \%$ of these dentists had recorded their suspicions in the clinical notes, which is higher than found in 2005. ${ }^{9}$ Dental defence organisations stress the importance of maintaining accurate records. In suspected cases of child abuse/ neglect it is important not only to document the clinical findings and supplement these with clinical images where possible but also to include what dental advice (for example, regarding diet and oral hygiene) has been given to the parent/caregiver. This is especially important in cases where the examining dentist may be called to give evidence in a CP case conference or hearing, as otherwise the parent or caregiver could argue that they had never been told what dental care, dietary modifications or oral hygiene measures were necessary.

It was the perception of the majority of respondents that children who are abused or neglected have a higher caries risk. Previous work by Green et al., ${ }^{6}$ ValenciaRojas et al., ${ }^{7}$ and Montecchi et al. ${ }^{8}$ have shown this to be the case in the USA, Canada and Italy respectively. The authors are currently involved in research to find out if this is the case in Scotland.

\section{Factors influencing practice}

The most common reason for not referring a suspected case of child abuse/neglect was lack of certainty of the diagnosis. Having had CP training did not appear to make a significant difference to this barrier despite dentists attending these courses being assured that it is not their responsibility to diagnose child abuse. This was also the most common reason for not referring in $2005 ;{ }^{9}$ however, the proportion of dentists who cited this as a reason is 9\% lower in this study.

Fear of violence to the child and fear of consequences to the child from the involvement of statutory agencies were the second and third most commonly cited reasons for not referring. The proportion that cited fear of violence to the child was higher than that reported in the 2005 study $^{9}$ and this may reflect recent high profile deaths of children at the hands of their abusers in the UK.

The fact that GDPs are still concerned about the consequences to children from the involvement of statutory agencies may suggest that more inter-agency training is required. The topic of 'What happens next?' is covered in section three of Child protection and the dental team ${ }^{20}$ and is also covered in CP training, but as this is something the dentist cannot control there may need to be further reassurances given about what happens after GDPs raise a concern. These reassurances can come from the national statistics for Social Work in Scotland which demonstrate that in the year 2010/11 out of 5,234 initial and prebirth case conferences in Scotland, only 3,884 children's names were added to the child protection register, and many of these children were on the register for less than a year. ${ }^{24}$

Severe, untreated dental caries on its own is very concerning but it may also be part of the picture of generalised neglect and this has been well described in recent literature..$^{20,21,25}$ If a dentist has pointed out a child's dental problems and offered appropriate and acceptable treatment there are various factors that may then lead the dentist to have concerns about the child. In this study we asked the GDPs about four of these factors which are mentioned in the BSPD policy document ${ }^{21}$ and Child protection and the dental team. ${ }^{20}$ Nearly half of all the GDPs answering this question would be concerned by irregular attendance, failure to complete treatment, and returning-inpain at repeated intervals with less being concerned about repeat GAs for extractions. A significantly higher proportion of GDPs who had child protection training or had read Child protection and the dental team were concerned about these issues compared to those without training or who had not read Child protection and the dental team. All these factors are indicators of dental neglect. ${ }^{20,21}$ This suggests training in $\mathrm{CP} /$ reading the manual makes dentists more aware of the issue of dental neglect on its own, and as part of the wider picture of general neglect. 


\section{Child protection procedures}

The majority of GDPs in this study would refer a suspected case of child abuse/ neglect to their child protection advisor with the next most common referral agency being social work. This is encouraging as this study has already shown that the biggest barrier to referral is uncertainty over the diagnosis of abuse/neglect, so discussing your concerns with someone who is experienced in $\mathrm{CP}$ can be very reassuring for the dentist. This also ensures that each case can be investigated appropriately. Child protection advisors usually have a background in nursing and postgraduate qualifications in CP. In Greater Glasgow and Clyde there are six CP Advisors who all have a background in health visiting and, as well as their postgraduate qualifications, they have many years of experience in supporting and advising their colleagues in the health service. In other areas a similar role is that of the lead nurse for child protection.

Although 60\% of respondents would refer suspected cases to their $\mathrm{CP}$ advisor only $31 \%$ knew who this person was. A significantly higher proportion of GDPs with training or who had read Child protection and the dental team knew who their $\mathrm{CP}$ advisor was. Identifying your local CP advisor is emphasised in child protection training. Additionally, in Child protection and the dental team an example flow chart of what to do if you have concerns about a child's welfare has a space to allow GDPs to write in the names and contact numbers of their local child protection nurse and in Scotland the details of the $\mathrm{CP}$ advisor could also be written here.

In this study $84 \%$ of respondents would prefer to discuss their concerns with a dental colleague before referring a suspicious case. It is likely that dentists feel more comfortable discussing their concerns with someone whose responsibilities and service they understand rather than a service they may never have dealt with. Similarly when the GDPs were asked if there was anyone not mentioned on the questionnaire that they would discuss a suspicious case with or refer a case to the most common answer given was the child's GMP. However GMPs may have similar barriers to referral as GDPs and therefore sharing information with a local CP nurse or advisor may be more beneficial. It is heartening to note that almost two thirds of dentists are willing to get involved in detecting neglect despite the barriers that they feel stand in the way of referring concerning cases.

\section{CONCLUSIONS}

Dentists in Scotland appear to be suspecting and referring more cases of child abuse/ neglect than previously; however similar barriers to referral still exist. More dentists are receiving training on $\mathrm{CP}$ but there remains a very strong desire for further training. Most dentists also perceive that abused/neglected children have a higher caries increment. The majority are willing to get involved in detecting neglect.

1. da Fonseca M A, Feigal R J, ten Bensel R W. Dental aspects of 1248 cases of child maltreatment on file at a major county hospital. Pediatr Dent 1992; 14: 152-157.

2. Jessee $S$ A. Child abuse and neglect: implications for the dental profession. Tex Dent J 1999; 116: 40-46.

3. Senn D R, McDowell J D, Alder M E. Dentistry's role in the recognition and reporting of domestic violence, abuse, and neglect. Dent Clin North Am. 2001; 45: 343-363.

4. Cairns A M, Mok J Y O, Welbury R R. Injuries to the head, face, mouth and neck in physically abused children in a community setting. Int J Paediatr Dent 2005; 15: 310-318.

5. Balmer R, Gibson E, Harris J. Understanding child neglect. Current perspectives in dentistry. Prim Dent Care 2010; 17: 105-109.

6. Greene P E, Chisick M C, Aaron G R. A comparison of oral health status and need for dental care between abused/neglected children and non-abused/nonneglected children. Pediatr Dent 1994; 16: 41-45.

7. Montecchi P P, Di Trani M, Sarzi Amade D, Bufacchi C, Montecchi F, Polimeni A. The dentist's role in recognizing childhood abuses: study on the dental health of children victims of abuse and witnesses to violence. Eur J Paediatr Dent 2009; 10: 185-187.

8. Valencia-Rojas N, Lawrence H P, Goodman D. Prevalence of early childhood caries in a population of children with history of maltreatment. J Public Health Dent 2008; 68: 94-101.

9. Cairns A M, Mok J Y Q, Welbury R R. The denta practitioner and child protection in Scotland. Br Dent J 2005; 199: 517-520.
10. Welbury R R, MacAskill S G, Murphy J M et al. 2003. General dental practitioners' perception of their role within child protection: a qualitative study. Eur J Paediatr Dent 2003; 4: 89-95.

11. Harris J C, Elcock C, Sidebotham P D, Welbury R R. 2009b. Safeguarding children in dentistry: I. Child protection training, experience and practice of dental professionals with an interest in paediatric dentistry. Br Dent J 2009; 206: 409-414.

12. Chadwick B L, Davies J, Bhatia S K, Rooney C, McCusker N. Child protection: training and experiences of dental therapists. Br Dent J 2009; 207: E6.

13. Saxe M D, McCourt J W. Child abuse: a survey of ASDC members and a diagnostic-data-assessment for dentists. ASDC J Dent Child 1991; 58: 361-366.

14. Von Burg M M, Hibbard R A. Child abuse education: do not overlook dental professionals. ASDC J Dent Child 1995; 62: 57-63.

15. John V, Messer L B, Arora R et al. Child abuse and dentistry: a study of knowledge and attitudes among dentists in Victoria, Australia. Aust Dent J 1999; 44: 259-267.

16. Kilpatrick N M, Scott J, Robinson S. Child protection: a survey of experience and knowledge within the dental profession of New South Wales, Australia. Int J Paediatr Dent 1999; 9: 153-159.

17. Owais A I N, Qudeimat M A, Qodceih S. Dentists' involvement in identification and reporting of child physical abuse: Jordan as a case study. Int J Paediatr Dent 2009; 19: 291-296.

18. Uldum B, Christensen H N, Welbury R, Poulsen S. Danish dentists' and dental hygienists' knowledge of and experience with suspicion of child abuse or neglect. Int J Paediatr Dent 2010; 20: 361-365.

19. Laud A, Gizani S, Maragkou S, Welbury R, Papagiannoulis $L$. Child protection training, experience, and personal views of dentists in the prefecture of Attica, Greece. Int J Paediatr Dent 2012; doi: 10.1111/j.13651263X.2012.01225.x.

20. Harris J, Sidebotham P, Welbury R et al. Child protection and the dental team. An introduction to safeguarding children in dental practice. Sheffield: Committee of Postgraduate Dental Deans and Directors, 2006. Online information available at http://www.cpdt.org.uk (accessed April 2013).

21. Harris J C, Balmer R C, Sidebotham P D. British Society of Paediatric Dentistry: a policy document on dental neglect in children. Int J Paediatr Dent 2009; D0I: 10.111/j. 1365X.2009.00996.x. Article available online at http://www.bspd.co.uk/LinkClick. aspx?fileticket=P2H2L6M4ISO\%3d\&tabid=62 (accessed May 2013).

22. General Dental Council, 2008. Statement on Child Protection and Vulnerable Adults. Online information available at http://www.gdc-uk.org/ Newsandpublications/Publications/Publications/standards\%20childprotectMay10.pdf (accessed April 2013).

23. ISD Scotland. Dental Workforce. ISD Scotland Dental Workforce 2011. Information available online at http://www.isdscotland.org/Health-Topics/ Workforce/Dental-Workforce/ (accessed April 2013).

24. Scottish Government. Children's Social Work Statistics Scotland, No. 1: 2012 Edition. Information available online at http://www.scotland.gov.uk/ Publications/2012/02/7586 (accessed April 2013).

25. National Collaborating Centre for Women's and Children's Health. When to suspect child maltreatment: full guidance. Clinical Guideline 89. National Institute for Health and Clinical Excellence. Royal College of Obstetricians and Gynaecologists: London, 2009 